\title{
PROBLEMATA

\section{COMUNIDADE (GEMEINDE) ENTRE LÓGICA E POLÍTICA NAS LIÇÕES SOBRE A FILOSOFIA DA RELIGIÃO DE HEGEL}

\section{COMMUNITY (GEMEINDE) BETWEEN LOGIC AND POLITICS IN HEGEL'S LECTURES ON THE PHILOSOPHY OF RELIGION}

\author{
Rodrygo Rocha Macedo ${ }^{1}$
}

Recebido em: 04/2020

Aprovado em: 11/2020

\begin{abstract}
Resumo: O presente artigo tem o propósito de explicitar como o projeto político de Estado que Hegel delineia na Filosofia do Direito (1821) é retomado sob o conceito de "comunidade" (Gemeinde) nas Lições sobre a Filosofia da Religião (1821-1832) a partir do uso dos silogismos sobre a criação e salvação do mundo apresentados na Enciclopédia das Ciências Filosóficas (1830). $\mathrm{O}$ Estado racional, fundando-se nas diferentes dimensões da vida humana e reconhecendo-as como suas próprias, materializa um projeto coletivo viável somente quando as liberdades individuais são resguardadas. Na Filosofia do direito, a realização do Estado se dá pelo acúmulo de etapas prévias de manifestação da liberdade, como é o caso da vontade, a qual abrirá caminho para a moral e a eticidade. Por outro lado, Hegel, nas aulas que compõem as Lições sobre a Filosofia da Religião, se deterá no conceito de "comunidade". Assim como o Estado, a comunidade também é um arranjo social, com ritos e normas próprios, cujos participantes adquirem senso de pertença e unidade. Com evidências de propósito semelhante ao Estado, a meta da comunidade é a manutenção do grupo a partir de uma ordem constituída e coletivamente assimilada. Se a comunidade possui um papel político, ele seria melhor visualizado quando a teoria política de Hegel se conecta com a filosofia da religião a partir dos elementos "liberdade", "finito", "infinito", "conceito" e "verdade" da lógica de Hegel.
\end{abstract}

Palavras-chave: Hegel, política, religião, lógica, comunidade.

\begin{abstract}
This article aims to explain how the political project of State that Hegel outlines in the Philosophy of Right (1821) is recovered by the concept of "community" (Gemeinde) in the Lectures on the Philosophy of Religion (1821-1832) with the use of syllogisms of creation and redemption of world as they are presented in the Encyclopedia of Philosophical Sciences (1830). Once the rational State is grounded on different dimensions of human life, it recognizes them as its own, materializing a viable collective project only when individual freedoms are warranted. According to Philosophy of Right, the effectiveness of the State occurs through the collecting of previous stages concerning the actualization of freedom. It is applied to the will, which paves the way for morality and ethical life. On the other hand, Hegel, in the classes that constitute the Lectures on the Philosophy of Religion, will focus on the concept of "community". In the same way as the State, the community is also a social arrangement, with its own rites and rules, whose participants acquire a sense of belonging and unity. By evidencing similar purposes to the State, the community's goal is to maintain the group based on a constituted and collectively assimilated order. Whether the community has a political role, therefore, this aspect is best seen when Hegel's political theory is
\end{abstract}

\footnotetext{
${ }^{1}$ Doutorando na Universidade Federal de São Carlos, pesquisador visitante em Brown University. E-mail: rodrygorochamacedo@gmail.com.
} 
connected with the philosophy of religion in accordance with the elements "freedom", "finite", "infinite", "concept" and "truth" identified in Hegel's logic.

Keywords: Hegel, politics, religion, logic, community.

\section{Introdução: coexistência entre Estado e Igreja como problema em Hegel}

$\mathrm{Na}$ teoria política de Hegel, o Estado tem por função assegurar a integridade dos seus cidadãos, perfazendo o arranjo social no qual a liberdade humana é promovida e preservada por instituições aplicadoras de leis. Compreendido na Enciclopédia das ciências filosóficas em compêndio (1830) como o transcurso realizado da eticidade, o Estado possuiria a sua "substancialidade" equivalente à "Religião", sendo ela a base destes elementos para a autoconsciência (Enz § 552; Enc-III, pp. 326-327)². Estes são os aspectos que, consoante Hegel, lançam os fundamentos comuns ao Governo e à Igreja, indicando também um produto posterior da parceria entre estas duas esferas, contrapostas em um primeiro momento, mas posteriormente reconciliadas em uma mesma unidade (cf. LFR-I, p. 133). Isto porque o espírito da Religião é o "espírito total”, definido como movimento em direção ao seu próprio saber emsi $(P h G \S 680 ; F E$, p. 462).

Se, por um lado, o Estado vem a ser a atualização do movimento de reconhecimento de cada indivíduo em relação aos outros, como resultado do compromisso das pessoas em integrarse à comunidade, por outro lado, a religião, expressão pessoal da espiritualidade que viabiliza uma percepção dos sujeitos como "irmãos" e iguais entre si, aparece no trecho anteriormente citado da Enciclopédia cumprindo a função de elemento associado à eticidade, precedendo a formação do Estado e condicionando a efetividade desse arranjo político à sua lei orgânica maior, a Constituição (Verfassung) (cf. Enz §§ 517, 552; Enc-III, pp. 297, 326-327).

Hegel não apenas vislumbra na religião o elemento constituinte da estrutura política de uma coletividade, mas também defende que ela deveria ser assegurada pelo Estado. Dado que o ente estatal é o promotor do direito e das liberdades, todas as outras expressões socioculturais, entre elas as manifestações de culto, devem afluir nele e a ele submeter-se. O Estado, assim

\footnotetext{
${ }^{2}$ As citações da obra de Hegel, acompanhadas por parágrafo ou página (quando houver), obedecem doravante às seguintes abreviaturas: Enzyklopädie der philosophischen Wissenchaften im Grundrisse (Enz); Enciclopédia das Ciências Filosóficas em Compêndio (1830)-I-II-III (Enc); Grundlinien der Philosophie des Rechts (GPhR); Filosofia do Direito (FD); Philosophy of Right (PR); Phänomenologie des Geistes (PhG); Fenomenologia do Espírito (FE); Vorlesungen über die Philosophie der Religion I-II-III, (Revisão de Walter Jaeschke) (VPhR); Lecciones sobre Filosofia de la Religión (LFR); Escritos de juventud (EJ); Wissenschaft der Logik I-II (WdL); Ciência de la Lógica (CL); Lecciones sobre la Filosofia de la Historia Universal (LFHU).
} 
descreve Hegel no início do $§ 270$ da Filosofia do Direito (1821), conflui para o "interesse universal", mas a sua substancialidade (a lógica interna da sua razão de existir que, para todos os efeitos, deve ser expressamente compreendida como necessária) direciona-se à conservação das particularidades, pois no Estado o que é universal e o que é particular se reconhecem um ao outro.

Nesse sentido, a religião seria um elemento estratégico de interesse estatal por justamente possuir condições de fornecer às pessoas, pelos mandamentos basilares de amar a Deus e ao próximo, uma perspectiva de compreensão das relações de autoridade e associação comunitária. Essa seria a razão pela qual Hegel indica que o Estado precisa da manifestação religiosa ou da fé: realizar um apelo ao interior e ao sentimento dos cidadãos de modo que eles adotem práticas intersubjetivas em prol da coesão social. Religião e Estado se apresentariam como estruturas sociais que se confirmariam mutuamente. Assim, o $§ 270$ da Filosofia do Direito permite inferir que o Estado, não repelindo a religião como a história assim comprova, mas trazendo-a para junto de seu âmbito de atuação, faz com que ela o auxilie a conduzir a liberdade humana ao autoconhecimento e à realização das suas particularidades, fortalecendo os elos sociais e também jurídicos entre os indivíduos, fatores que cooperam para a manutenção da ordem pública.

Uma instituição social que dinamiza dentro de si as esferas secular e espiritual sem interferências ou ingerências poderia ser vislumbrada nas Lições sobre a filosofia da religião (1821-1832) de Hegel na figura da "comunidade" (Gemeinde). Contudo, levanta-se a seguinte questão: como Estado e religião, na teoria de Hegel, podem operar em uma conjunção sem interferências entre si, de modo que a comunidade, resultante desse consórcio, seja simultaneamente política e religiosa? Certas passagens da Enciclopédia poderiam lançar luzes sobre essa questão: “a necessidade de compreender a Lógica, em um sentido mais profundo que o da ciência do pensar puramente formal, é ocasionada pelo interesse da religião, do direito, do Estado, e da vida ética” (Enz $§ 19$ Z; Enc-I, pp. 66-67). A figura do Estado recupera os movimentos que Hegel vem descrevendo na sua demonstração lógica do pensar. O Estado agora se torna um sistema de silogismos: a) o singular (pessoa), mediante sua particularidade (necessidade que redunda na sociedade civil) com o universal (a sociedade política, o direito, a lei, o governo); b) a vontade dos indivíduos, que é o elemento mediatizante, que implementa as necessidades; c) o universal (Estado, direito, governo), meio-termo no qual os indivíduos e sua satisfação mantêm sua realidade (cf. Enz § 198; Enc-I, pp. 337-338). Dessa forma, a religião possui um vínculo com o Estado que é também lógico. 
No entanto, aspecto de relevo deve ser considerado: a noção de Deus ocupa lugar central em um debate no qual a religião é tema integrante. Quando se quer identificar a implicação intersubjetiva e política da religião na produção escrita de Hegel, a noção hegeliana de divindade e sua interação com o humano possuem a função de explicar como os indivíduos lidam como a dimensão da transcendência (e como o pensamento humano) transforma essa compreensão de Deus em dinâmica social. O intento deste artigo é explorar, na produção escrita de Hegel, conceitos recorrentes aos âmbitos da política e da religião mediante a noção de divindade. Do contrário, seria um risco admitir, como adverte Stephen Houlgate, que Deus possa ser tomado por Hegel como "espírito em geral”, pois isto tornaria o autor alemão um escolástico tardio, algo do qual não se possuem elementos para confirmar (cf. HOULGATE, 2006, pp. 70-71). Cumpre ressaltar que este artigo é motivado também a identificar elementos da lógica e da política de Hegel que auxiliem na compreensão do conceito de comunidade como arranjo social. Dessa forma, o artigo terá as seguintes seções: os elementos lógicos que conectam aspectos da filosofia da religião e filosofia política; uma explanação sobre os elementos constituintes do Estado; a noção de comunidade tal como ela é apresentada nas Lições sobre a Filosofia da Religião.

\section{A lógica hegeliana como índice de conexão entre política e religião}

Na obra de Hegel a liberdade é identificada em seus próprios movimentos. Presente no desejo mais indefinido do indivíduo, a liberdade toma a dimensão de interesses, valores e normas, ramificando-se em manifestações de moral, leis e instituições, como agir espiritual e consciente.

Há um inegável interesse histórico dos filósofos em conectar lógica, religião (em seus aspectos metafísicos) e política em um sistema de pensamento. Miguel Giusti observa ser Aristóteles um dos primeiros filósofos que tenta fazer uma divisão sistemática das ciências. A metafísica aparece como disciplina, compreendida como "teologia" e "filosofia primeira". Por querer contemplar a causa das coisas, a teologia era considerada a ciência que trata da substância e de Deus como "motor imóvel”. A metafísica, relata Giusti, era ciência para Aristóteles, mas a lógica não, compreendida como uma arte ou técnica argumentativa. Já a política cumpria o papel de filosofia "prática", enquanto a metafísica recebia a denominação de filosofia "teórica". Na modernidade, Christian Wolff foi, entre os pensadores, quem mais teria aproximado lógica e metafísica ao combinar o projeto de mathesis universalis de seu professor 
Leibniz com os elementos escolásticos fundamentados em Aristóteles. Kant, por sua vez, teria compreendido que a lógica, sob a chave transcendental e na busca das bases do entendimento, inseria as figuras da alma, Deus e do mundo como domínios da metaphysica specialis de Wolff (cf. GIUSTI, 1994, pp. 50-58). Hegel confirma na Ciência da Lógica (1812-1816) sua adesão parcial ao projeto kantiano quando expressa a lógica como constituinte da metafísica propriamente como filosofia puramente especulativa (cf. $W d L-I$, p. 16; CL, p. 38).

A própria filosofia é explicada por Hegel como atividade do pensar que reivindica uma forma peculiar de realizar sua tarefa (cf. Enz § 5; Enc-I, pp. 43-44). Menos óbvio é ver que "subjetividade" em Hegel é geralmente "metafísica" e "moral-histórica" (ou "lógica" e “objetiva" nas palavras de Hegel). Diferentemente da religião ou das ciências, a filosofia dispensaria pressupostos, transformando representações em pensamento, este último um princípio que inclui ação. Enquanto movimento, a ação garante às categorias lógicas operativas não estarem restritas a uma dimensão transcendente, mas serem localizadas em todos os lugares e usadas na vida cotidiana. Assim, os conceitos operativos, por se conectarem à liberdade, são ativos no indivíduo (WdL-I, p. 25; CL, pp. 46-47; cf. FERRARIN, 2001, pp. 18, 60-67). A lógica de Hegel "não é uma ontologia, mas a lógica do pensar" estabelecido na realidade (FERRARIN, 2001, p. 71):

\footnotetext{
A lógica tem três aspectos: a) o aspecto da abstração e do entendimento, b) o aspecto dialético ou racional negativo, [e] c) o aspecto especulativo ou positivamente racional. Este três aspectos constituem três partes da lógica, mas como momentos de tudo o que é logicamente real; i.e., de todo conceito de tudo que é verdadeiro em geral (Enz \$79 A; Enc-I, p. 159).
}

Admitindo que o real, o racional e o verdadeiro pertencem ao mesmo âmbito de reflexão, e uma vez que o conceito de Deus ou objetividade divina contém a verdade, logo a realidade e a racionalidade estão implicados em Deus. Alfredo Ferrarin admite que o conceito de divindade é contemplado no espírito absoluto como estágio no qual o natural e o espiritual são pensados conjuntamente (cf. FERRARIN, 2001, p. 67). Assim, Deus emerge da lógica como fonte emissora de qualidade real enquanto atividade, criação e poder. Agindo como fonte qualitativa, Deus dá abundantemente características para si próprio, o que faz com que o conceito divino adquira determinações. Deus, ao determinar-se, criaria limites qualitativos entre si e o mundo: isto significa uma constituição do negativo (Deus existente implica coisas que não são propriamente Deus). Há portanto a produção de um “outro”. Essa determinação só pode ocorrer porque Deus é Deus em relação a um outro, o que faz com que surja um conteúdo 
que é relacional (cf. $W d L-I$, p. 86; $C L$, pp. 108-109). Contudo, Deus, constituindo-se a si e ao mundo como um outro de si, perfaz apenas o início de um movimento da liberdade (que se dá sob a forma de espírito), cuja decorrência é aproximar, conectar e, finalmente, reunir o próprio ente divino com o mundo.

Hegel edifica na lógica uma relação entre o pensamento absoluto (divino) e o pensamento humano (não-divino e componente do mundo) como concretização do universal, com presença do infinito no finito. Tal só pode ser realizado se o finito é tanto racional como empírico-especulativo (cf. FERRARIN, 2001, p. 78). Essa "simbiose" entre o divino e o humano se dá pela consciência. Partindo da imediação, ela é levada por seu caminho ao conhecimento absoluto como sua verdade mais íntima. Para a consciência, o começo depende de seu resultado, no qual o "primeiro" se transforma em "último", e o "último" em "primeiro". Assim, o que é fundamento da consciência se torna em seu próprio resultado (WdL-I, p. 70; $C L$, p. 92). A compreensão lógico-metafísica de espírito é a sua "conexão de substância e subjetividade", elementos que existem tanto em Deus como no ser humano (cf. BUCHWALTER, 2018, p. 33).

Consoante Bernard Bourgeois, em Hegel, o indivíduo, posicionando-se diante da dimensão da transcendência, é o sujeito pensante e se funda no conceito de absoluto, o qual, por sua vez, é o princípio da oposição. O conhecimento do absoluto seria obra da pura positividade, que é a intuição intelectual. O absoluto hegeliano é estruturado de maneira análoga ao seu desdobramento igualmente regido pela "Ideia", ou seja, pela identidade racional da intuição e do conceito, e da diferença. A infinitude, como negação de si ou a subjetividade, está no coração do absoluto, do positivo, da substancialidade. Isto significa que a realização finalizada do absoluto é a realização como sujeito-objeto subjetivo, ou seja, a natureza ética (cf. BOURGEOIS, 1986, pp. 14; 167-171).

Hegel indica que o indivíduo, diante da dimensão da transcendência, funda-se no conceito de absoluto, que se posiciona como não humano (ou divino). Todavia, o conhecimento que o indivíduo recolhe do absoluto se dá mediante intuição intelectual. O absoluto hegeliano seria estruturado a partir da "Ideia". A infinitude, própria da transcendência, estaria no âmago do absoluto e, por consequência, da substancialidade. A realização do absoluto, portanto, seria a conexão entre sujeito e objeto em uma dimensão subjetiva, a saber, a natureza ética (cf. BOURGEOIS, 1986, pp. 167-171). Vale lembrar que, na religião “absoluta”, Deus se manifesta diante de Si e conhece a Si mesmo (cf. WILLIAMSON, 1984, p. 178).

O movimento de reconhecimento entre o divino e o humano ocupou a atenção de Hegel 
durante praticamente toda a sua produção escrita. Walter Jaeschke chega a afirmar que no ensaio Sobre as Maneiras Científicas de tratar o Direito Natural (1802-1803), anterior à Ciência da Lógica (1812-1816), Hegel admitiria que o espírito só é espírito "quando ele retorna a si após sua exteriorização, encontrando a si mesmo" (JAESCHKE, 1990, pp. 139-140, nossa tradução). Quer isto dizer que o movimento de Deus em direção ao homem e vice-versa começa a adquirir mais importância do que as partes implicadas "Deus" e "humano". Mais tarde, no Prefácio à Fenomenologia do espírito (1807), afirmando a substância também como sujeito, Hegel não só retiraria a preponderância que a substância até então possuía na filosofia moderna (como atesta o tratamento que Descartes e Spinoza deram a ela), como também indicaria a necessidade de haver um movimento entre divino e humano com o qual as Lições sobre a Filosofia da Religião tratam com mais vagar.

Abordar esse movimento de identificação entre divino e humano é introduzir o "conceito" de religião na lógica, o que implica desenvolver momentos sucessivamente dialéticos para ela: sua representação histórica (um relato de como a religião manifesta sua estrutra conceitual no mundo); o aprofundamento de seus aspectos científicos a partir dos quais são constituídas as relações dialéticas na consciência e na necessidade abstrata; o reconhecimento da verdade necessária concreta a partir da totalidade da religião (ou "ideia" dela) para que se compreenda aquilo que a constitui em nível absoluto (cf. CHAPELLE, 1964, vol. I, p. 193).

Se a liberdade é o modo como os processos sociais (dentre eles a identificação entre o divino e os humanos) efetivam-se na realidade, Hegel vê a necessidade de descrever, de forma ontológica, as suas etapas e seus componentes: para isso, Hegel faz uso da lógica. O objeto da ciência da lógica é a verdade. Mas existem questões que surgem da escolha dessa ferramenta. A primeira delas: qual a ponte entre o finito (na figura do indivíduo como elemento inicial de um sistema social) e o infinito (universal)? Uma resposta possível é Deus. Isso leva à segunda pergunta: como Deus pode ser conhecido para tornar-se essa ponte? Decerto tal não pode ser realizado com as virtudes da humildade e modéstia, imaginando-se que a consciência é insuficiente a ponto de não conseguir apreender a Deus. O pressuposto aqui é adotar a consciência tal como ela é descrita na Fenomenologia, que se movimenta em direção ao saber absoluto, ainda que o mundo pobre em certezas e verdade lhe seja desfavorável. Tal atitude implica realizar o trabalho amargo do espírito em buscar essa verdade, pois só o espírito pode conhecer o espírito (divino). E o conteúdo espiritual é Deus, mas somente no pensar e como pensar (cf. Enz § 19 A; Enc-I, pp. 65-66). 
A vontade como base do espírito objetivo (que redunda no Estado) é o agir já contemplado na autodeterminação do conceito descrita na Ciência da Lógica, tensionado entre a intenção subjetiva (Vorsatz) e intenção universal (Absicht). No § 553 da Enciclopédia, Hegel interrelacionará tais instâncias ao advertir que "o conceito de espírito possui sua própria realidade em espírito" (HERRMANN-SINAI, 2016, p. 164).

O direito, a moralidade e a eticidade (nas formas da família, sociedade civil e no Estado, que assimila os dois anteriores) ajudam o espírito a autoperceber-se. $\mathrm{O}$ elemento de mediação adequado a fazer essa ponte entre a autoconsciência (instância dedutiva) e o saber absoluto (confirmação da universalidade) é o conceito de Deus, do qual trata a religião. Isto porque a religião, para a autoconsciência, é a base da eticidade e do Estado. Deus age como elemento intermediador entre os sujeitos e o absoluto.

O conhecimento divino, de acordo com Evangelia Sembou, se atrela ao Estado e suas leis quando a coletividade de indivíduos suprassume sua própria finitude como "espírito público". Essa percepção grupal da autoconsciência já foi descrita por Hegel em seus escritos juvenis como já ocorrida entre os gregos. Como algo vivo e antiascético, tal percepção decorria da prática social chamada "religião pública", que dava aos indivíduos um senso de pertença, ampliando-se em todas as dimensões da existência de um cidadão grego, fosse nas instituições, nas práticas litúrgicas, nas atividades comerciais e políticas (cf. SEMBOU, 2017, pp. 26, 35). Hegel logo admitiu que a manifestação religiosa com consequências na vida política de um grupo nos moldes gregos não poderia ser repetida na modernidade, uma vez que a noção helênica de indivíduo como cidadão não era mais a mesma no contexto social europeu.

Nas Lições sobre a Filosofia da História Universal (1837), Hegel já havia descrito que o movimento da liberdade do espírito precisou sair do mundo greco-romano para a Idade Média. Tal período histórico estava sob o "Reino do Filho", cuja figura lógica do Cristo, como no silogismo trinitário da Enciclopédia, em seus $§ \S 567-570$, sai de si convertendo-se em "outro" distinto da figura divina, mas que após sua morte no mundo e pelo mundo retorna a si mesmo (Deus). O vazio deixado por Cristo é preenchido pela figura do Espírito, que funda um Reino (momento histórico) próprio, do qual a Reforma é parte. Hegel sublinha este período como como um tempo em que grupos e povos se aglutinam em torno da liberdade e da universalidade (cf. $L F H U$, p. 660). A religião protestante passa a fornecer a liberdade de consciência ao indivíduo, mas a consequência disso é a dissociação paulatina entre a vida pública religiosa e a vida pública política. Não há mais lugar para a religião pública helênica. A possibilidade de uma noção de cidadão moderno com a dimensão religiosa é vislumbrada na "comunidade", 
expressão social da religião após o estabelecimento histórico do Estado enquanto resultado das vontades individuais livres.

\section{O Estado hegeliano: realização não-conclusiva da liberdade?}

Dado que nas Lições sobre a Filosofia da Religião o movimento da liberdade perfaz a conexão das consciências (as dos seres humanos entre si e deles com a consciência divina), o elo social adquire importância lógica. A Filosofia do Direito tenta ampliar para o âmbito político o que Hegel expunha no Direito Natural, na Fenomenologia do Espírito e na Enciclopédia a respeito da resolução do movimento de reconhecimento de consciências. Uma vez que tal harmonização entre instâncias subjetivas só ocorre mediante a liberdade no âmbito do real, a Filosofia do Direito assume na obra de Hegel, para usar o termo de Phillippe Soual, o papel de "inventário" das aquisições principais que os governos europeus granjearam em prol da ordem social a partir da adoção de um sistema constitucional com separação de poderes, bem como o estímulo às liberdades individuais, principalmente na Inglaterra pós-Cromwell e na França republicana sob o cetro de Napoleão. O Estado da Filosofia do Direito não pode ser outro que não o Estado racional, que não só funda, como também reconhece todas as dimensões da vida humana como sendo suas próprias. A racionalidade estatal ocorre na medida que as liberdades individuais são reconhecidas. Se o Estado tem um sentido, é a disposição interior política que impele os seres humanos a realizar uma obra comum para que se tornem livres (cf. SOUAL, 2006, pp. 2-3). A Filosofia do Direito é tratada por Hegel, logo no Prefácio, como um Kompendium cujo objetivo é tratar do tema do direito e da sociedade de forma científica, de modo a evidenciar seus elos e conexões sobre o "espírito lógico" (GPhR pp. 11-12; FD, p. 32). Essa proposta lógica ressalta a intenção metodológica de explorar o automovimento do conceito.

Para evidenciar esse "espírito lógico" do Estado como resultado do conceito, Hegel se vale de uma exposição usada tanto na Fenomenologia como na Enciclopédia: o pensamento abstrato, com sua contradição e insuficiência, empreende uma autonegação e uma passagem a um nível mais concreto. Não se parte do positivo para dele derivar as consequências, mas o contrário, parte-se daquilo que não é para-si e cuja autonegação conduz ao verdadeiro. $\mathrm{O}$ absoluto, que é o "verdadeiro" (aqui, a vontade racional como Estado) dá-se como resultado de sua própria deposição a partir da figura mais abstrata na vontade imediata como direito da pessoa. A consequência dessa premissa ecoará mais adiante nas Lições sobre a Filosofia da 
Religião, quando a comunidade não se origina propriamente de Deus, mas do humano finito que tenta chegar a Deus, a saber, a ideia completa. O todo da ciência do Estado repousaria, portanto, sobre o espírito lógico (cf. SOUAL, 2006, p. 9).

Para culminar na forma coletiva máxima, que é o Estado, a liberdade da vontade toma a forma de "constituição política". É a constituição que faz da ideia de Estado se torne efetiva. Segundo o § 269 da Filosofia do Direito, na divisão de poderes admitida por Hegel (régio, governamental e legislativo ${ }^{3}$ ), existe uma harmonização de forças que faz com que o Estado se autoproduza e se conserve, comportando-se como um "organismo" (Organismus). A Filosofia do direito permite inferir que a ciência do direito possui uma existência histórica e localizada (Dasein) (cf. GIUSTI, 2013, p. 53).

Na Filosofia do direito, portanto, encontra-se a tarefa de descrever a estrutura política da sociedade a partir de uma perspectiva lógico-metafísica que não negligencie seu aspecto prático. É o que Hegel admite no início da "Introdução", ao afirmar que a ciência filosófica do direito tem por objeto "a ideia do direito, o conceito do direito e sua efetivação", e que como parte da filosofia, a ciência do direito também se ocupa da demonstração da verdade e do resultado dos assuntos jurídicos (GPhR $\S \S 1-2 ; F D$, pp. 47-48). Nesse âmbito, a liberdade tem proeminência: seu início é a vontade livre, que se conecta à religião ( GPhR §§ 4-5; FD, pp. 5658). O conteúdo da vontade reside no "eu" e indica o "querer algo". Hegel salienta o aspecto da vontade formal, que só passa a existir quando o "eu" se percebe como autoconsciência (GPhR §§ 8-9; FD, p. 61). Questão semelhante ocorre nos §§ 166-168 da Fenomenologia (FE, pp. 135-137), bem como nos $§ ~ 424-425$ da Enciclopédia (Enc-III, p. 195-197). Mas nestas obras, a ênfase se dá na consciência desejante. Na Filosofia do Direito, pelo contrário, o mundo jurídico é o âmbito principal, o terreno no qual a vontade se move.

Mas como uma vontade é materializadamente livre? Segundo o § 137 da Filosofia do Direito (FD, pp. 148-150), a consciência moral deve ocorrer a partir da vontade, uma disposição de espirito em direção ao bem. A “intenção" da consciência é a verdade, ainda ausente do mundo, mas cuja possibilidade de ocorrer no mundo está contida no Estado. O lado débil da consciência moral é que ela ainda se encontra apenas com uma indicação, pois não é efetiva ainda. Na sua restrição, a moralidade se identifica com a vontade subjetiva, pois ela executa uma aproximação jurídica aceitando ou rejeitando a norma (cf. WEBER, 1993, p. 82).

\footnotetext{
${ }^{3} \mathrm{O}$ poder régio seria o poder executivo, enquanto que o governamental teria as atribuições de um ministério do interior, que se ocupa de assuntos correntes e específicos de determinada nação. O poder judiciário como poder de Estado é inexistente em Hegel, visto que a aplicação das leis e resolução dos litígios era operacionalizado pelos tribunais, que integravam a sociedade civil-burguesa (cf. ROSENFIELD, 2010, pp. 18-19).
} 
A Filosofia do Direito e a Fenomenologia guardam proximidade quando tratam do bem. Se a vontade moral contém em si o bem-estar e o bem (GPhR § 114; FD, pp. 133-134), o bem é a ideia no interior da vontade particular, cuja essência é a liberdade realizada ou "o fim último absoluto do mundo" (GPhR $\S 124-125,129$; FD, pp. 139-141, 143). Hegel correlaciona o cristianismo com a inserção da liberdade subjetiva da vontade na consciência. A subjetividade é agora vista como elemento do bem-estar, pois aquilo que a autoconsciência mostra ao indivíduo como um bem pode ser ampliado para todos. A essência espiritual do bem é, portanto, o universal, pois faz os indivíduos tomarem nela consciência de sua singularidade ( $P h G \S \S 493$; FE, pp. 342-343). Esse bem que se instala na vontade é a eticidade, a "ideia da liberdade, enquanto bem vivente". A eticidade realiza a "liberdade que já se encontrava na autoconsciência" (GPhR $\S 142,144-145 ; F D$, p. 167).

O Estado é a efetividade da ideia ética, vontade manifesta, sendo o "racional em-si e para-si”. O Estado não ocorre a partir do contrato, mas muito antes (GPhR §§ 257-258; FD, pp. 229-233), vindo a ser a atualização do movimento de reconhecimento de cada indivíduo em relação ao todo. Dessa forma, o Estado só se faz pelo compromisso do indivíduo em integrarse à comunidade. Assim, uma interioridade cultivada (pela Bildung) e crítica constitui garantia contra as tentativas de sujeição do homem e condição da liberdade. A começar, como Denis Rosenfield alude, pelo "eu” que, em laborioso processo de autodeterminação, transforma-se em "pessoa" e em "sujeito". O sujeito seria o "termo médio entre a pessoa e o membro de uma comunidade". O eu, por sua vez, configuraria o fundamento da estrutura política moderna, encontrando-se nele a instância de enunciação da vontade, que é o próprio índice de movimento da liberdade. O objeto dessa vontade percorreria etapas prévias, passando pelo bem-estar, o bem em si, em um processo de purificação racional, até atingir sua forma ótima no Estado (cf. ROSENFIELD, 1995, p. 108-110).

O Estado moderno, confiando a vontade geral a si mesma, alinha-se à lógica de aproximação do infinito ao finito, de Deus ao humano. O Estado pode efetivamente decidir como uma dimensão total da vontade, pois legitimamente se encarna em vontades singulares, as únicas reais (muito embora Hegel discorde que exista a vontade coletiva diretamente real sem a existência do Estado). Dessa forma, o Estado é uma soma orgânica de indivíduos que, juntos, tendem sempre a eliminar o espectro do "outro" de si. Em uma dimensão coletiva na presença do Estado, o coletivo de indivíduos que possuem vontades específicas, a partir do momento em que se reconhecem sujeitos que podem partilhar de uma vontade semelhante e com os mesmos fins, passa a ser uma autoconsciência. Esse é o trabalho do espírito. A filosofia 
hegeliana da religião define Deus como estando em sua própria comunidade, um encaixe entre espírito infinito e finito. A comunidade materializa a definição de "religião" como uma unidade divina entre o ser humano e Deus (cf. BOURGEOIS, 2004, pp. 126, 255).

Todavia, o Estado apresenta certos limites: primeiro, a moralidade independe do Estado para existir, muito embora ela só se faça presente em um ambiente no qual alguma lei tenha vigência. As pessoas sempre saberão a necessidade de o Estado promulgar certas normas, mesmo que elas ainda não existam. Além disso, o Estado historicamente comprovou não possuir instrumentos para fazer com que os cidadãos espontaneamente convivam em união. $\mathrm{O}$ Estado, para manter os indivíduos unidos no mesmo intento e com as mesmas vontades, teria que legislar a moralidade. Tais disposições podem ser estimuladas pelo Estado por meios indiretos, sendo a religião o estimulador por excelência, caso estivesse submetido ao Estado. Certas instituições, tais como família, estamentos e guildas servem de mediação entre os indivíduos e o Estado, precisam estar integradas no corpo político, sem as quais a erosão do sentimento de pertença é inevitável. Mas em tal contexto o espírito se vê impedido de efetivar a liberdade. Uma vez que o Estado é a expressão da consciência do espírito, logo religião e Estado são expressões da mesma consciência (cf. LEWIS, 2011, pp. 42, 106, 131). Se a liberdade, o Estado e a religião coincidem (GPhR § 360; FD, pp. 313-314), algo deve promover essa harmonização de faces da vida ética. As Lições sobre a Filosofia da Religião indicam que a instância na qual estas rotinas da eticidade também estão presentes seja a "comunidade".

\section{A “comunidade” (Gemeinde) no espectro lógico-político das Lições}

O período em que Hegel se instala em Berlim delineia a maturidade de sua obra, que se comporta como sua fase juvenil por dois aspectos: ela mostra a extensão de temas de seus primeiros escritos, tais quais política, arte, história e religião, como seguem as notas de aula e cadernos de seus alunos legados à posteridade; certos tópicos de política e religião passam a caminhar com mais proximidade, evidenciados como conteúdos centrais de especulação filosófica apenas vistos na produção da mocidade do autor. A relação entre religião e Estado ganha um curso, cujas anotações das aulas posteriormente se encontrarão sob o nome de Lições sobre a Filosofia da Religião. Hegel ministra tal curso em quatro ocasiões nos respectivos anos 1821, 1824, 1827 e 1831. As lições de 1821 são compostas pelas anotações de Hegel e seus alunos, mas a versão de 1831, por sua vez, corresponde às anotações de aula de David Friedrich Strauss (cf. LEWIS, 2011, p. 107). 
As Lições sobre a Filosofia da Religião apresentam como Hegel continua operando no movimento lógico: se somente o ser humano pensa, somente ele possui religião. Logo, o âmago da religião está no pensar. A razão humana, bem como sua consciência espiritual e a consciência de sua essência, é o divino no indivíduo. A filosofia, dessa forma, ajudaria na inserção da consciência divina nos seres humanos. Dado que o objeto da religião é por si e para si o fim absoluto, a "verdade eterna" e a consciência dessa verdade, aquilo que é "absolutamente livre", a religião cristã teria essencialmente em si o seu próprio conhecimento. Sem ela, o ânimo humano estaria repleto de consciência divina e substancial sem coerência. Por conta dessa desorganização de conteúdo, a religião se faz necessária, visto ser a relação da consciência humana com Deus (cf. LFR-I, pp. 57-58).

Hegel retoma nas Lições sobre a filosofia da religião um tema tratado em seus escritos de juventude: como a religião deveria ser "do povo" e não friamente institucionalizada. O escrito A Vida de Jesus (1795) apresentaria as ações e discursos de Jesus sob o prisma da razão prática (kantiana), vislumbrando na lei moral e na pureza o único fundamento da religião e do cristianismo (cf. VERRA, 1988, pp. 8-9). A tarefa da reforma moral e espiritual sugerida por Hegel é incumbida à religião subjetiva (a religião do "coração"), e não somente à sua versão objetiva. Muito mais do que dos eruditos, a reforma espiritual surge das práticas populares (de onde vem o uso do termo Volksreligion), ideia que Hegel provavelmente tomou de Rousseau ${ }^{4}$.

Se a humanidade conseguiu alcançar a forma mais otimizada de coesão na "república antiga", e se tal foi proporcionada pela educação em prol da liberdade, o resultado feliz dessa harmonia social só poderia ser proporcionado pela e na religião (BOURGEOIS, 1970, pp. 3031). A comunidade cristã, por exemplo, por não estar objetivada no mundo, precisava de um Deus no qual manifestasse seu próprio caráter, bem como o da relação mútua de seus membros, a saber, o amor excludente (cf. EJ, pp. 373-374). Hegel, retornando à questão da norma, afirma ter estudado a Crítica da Razão Prática (1788) e Fundamentação da Metafísica dos Costumes (1785) de Kant, e incumbe-se a reunir a "legalidade" do direito positivo e a "moralidade", que é boa ou má, sob um conceito superior. Em tais comentários, chamou esse conceito simplesmente "vida" (cf. EJ, p. 258) e, posteriormente, "eticidade". A vida se daria na comunidade, não em uma divisão social entre instâncias política e eclesiástica. Essa será uma importante definição para o elo social com ressonância na obra de Hegel até sua produção

\footnotetext{
${ }^{4}$ A esse respeito, a obra Religião e política em Rousseau (2013) do prof. Thomaz Kawauche mapeia nas práticas religiosas e na tolerância confessional o elemento social aglutinador de um corpo político a partir do conceito de "religião civil" presente no Contrato social, do filósofo genebrino.
} 
madura.

O debate que Hegel alimenta em seus escritos juvenis mostram o indivíduo-cidadão de uma república que anda de mãos dadas com a igreja, algo muito próximo do cidadão de Aristóteles, para quem a polis teria mais semelhança com uma igreja do que com um Estado, tendo em vista a ênfase na moral e nas virtudes (cf. ALLAN, 1965, pp. 56, 59). Tais ideias a respeito das consequências políticas da prática religiosa aliada ao Estado reaparecem em toda sua força nas Lições sobre a Filosofia da Religião, que delimita três momentos de religião: a religião enquanto conceito, a religião determinada e a religião consumada (manifesta, ou como ela se efetiva historicamente $)^{5}$. Importa destacar que Hegel contempla tanto a religião na sua acepção conceitual como ideia e, também, como expressão sócio-temporal. As Lições sobre a Filosofia da Religião de 1821 até 1831 apresentam coesão conceitual indicando, pelo menos, duas dimensões para a religião: a) afirmação de Deus como verdade e b) momento de mutualidade entre consciência divina e humana. Na religião consumada, o espírito é manifesto para si como finito em forma de "comunidade". Nela, "a natureza eterna e substancial do Espírito" é o que, naquele preciso momento, "chegou à consciência" (LFR-III, p. 83). Como aduz Ricardo Ferrara, existe um "ser-aí temporal” intrínseco à manifestação da da comunidade (cf. FERRARA, 1985, p. Xxxiii).

Nas Lições de 1824 e 1827, a religião consumada apresenta evidência de cumprir o estágio completo da manifestação da transcendência entre indivíduos, resultando em associação entre o indivíduo e a dimensão absoluta por um viés lógico:

a religião que é o ser do espírito para si mesmo, a religião que chegou a ser objetiva a si mesma. Denominamos religião - e tal é o conceito desta religião - à consciência de Deus, da essência absoluta; consciência é a diferenciação em si, o espírito que se diferencia. Deus, pois, existe como consciência, ou a consciência de Deus significa imediatamente que a consciência finita tem como objeto este Deus, sua essência, sabe disso como sua essência e se objetiva. [...] $\mathrm{O}$ espírito universal e o singular, infinito e finito são inseparáveis, sua identidade absoluta é a religião, e a religião absoluta consiste em ter isto como conteúdo (LFR-III, pp. 95-97, nossa tradução).

Esta "identidade absoluta" que, de algum modo, se conecta na comunidade, resultaria da atividade de um espírito que se diferencia e reconhece sua essência. Tal constatação

\footnotetext{
${ }^{5}$ É importante sublinhar que o conceito de religião foi trabalhado com mais intensidade na fase hegeliana de Berlim. Um dos argumentos favoráveis a isso reside no fato de que a religião, enquanto conceito, não teria sido explorada na Fenomenologia, tampouco na Filosofia do Espírito, texto escrito em 1805-1806 que posteriormente integrará a Enciclopédia (cf. JAESCHKE, 1990, p. 216), obras em que há considerável atenção para o tema.
} 
implicaria um índice de movimento chamado "vida", a qual, já presente nos escritos juvenis Positividade da religião cristã e $O$ espírito do cristianismo e seu destino, passou a ser incluída às concepções correlatas do legalismo judaico e da moralidade kantiana, alcançando uma primeira reunificação em Jesus, figura do amor ético, que reconciliava as virtudes, a lei, a pena e o destino. Não obstante, o destino de Cristo que, por ensinar a separação do mundo, é condenado e crucificado pelo Estado, tenha um projeto de reunificação viabilizado na "comunidade" (Gemeinde) (cf. FERRARA, 1984, p. v).

A própria noção de vida se encontra no silogismo que trata da razão ou pensamento, visto que pensamento, porque se move, é: a) substância universal ou princípio de um enunciado (U); b) a particularidade ou índice de determinação do universal em uma situação dada (P); c) o indivíduo a quem o enunciado direciona um predicado (I). Admitindo-se a fórmula "Se $\mathrm{U}=$ $\mathrm{P}$ e $\mathrm{P}=\mathrm{I}$, então $\mathrm{U}=\mathrm{I}$ ”, encontra-se, portanto, o princípio de imediatidade ou identidade (universal), a sua diferenciação (no particular) e uma conseguinte síntese (correspondente ao indivíduo). O silogismo trata das estruturas e as relações do próprio pensamento como formas da ideia efetivada no mundo e na consciência. Dentre estas estruturas se encontra o espírito (cf. HODGSON, 2005, pp. 9-10). Do mesmo modo, Hegel insiste que a religião também pode conduzir os indivíduos a um repouso o infinito, que é Deus, dado que o finito reside no indivíduo.

A passagem que mostra forte conexão entre a religião e as formas silogísticas, com indicação de síntese entre o humano e o divino, ocorre na Enciclopédia, entre os $§ \S 567$ e 570. Nesta passagem, o espírito absoluto seria o "pressuposto" para o movimento no qual uma entidade subjetiva autônoma (Deus) cria outra subjetividade (o Filho). O segundo movimento é a criação da natureza (o mundo) como outro de si. Todavia, a alteridade intrínseca à natureza criada contém em si o "extremo da negatividade", ganhando autonomia como "o mal" (Enz §§ 567-568; Enc-III, pp. 348-349). Não obstante, a dinâmica da criação contém como "pressuposição" a substância universal, que impulsiona a morte do Filho na negatividade em prol de um retorno à universalidade e, por consequência, a inserção de um espírito "presente no mundo". Há uma verdade em si decorrente desse movimento de mediação, cujo resultado é a autoconsciência (Enz §§ 569-570; Enc-III, p. 349). Hegel estipula uma conclusão sobre estas operações deduzidas da narrativa do projeto de criação e salvação do mundo na perspectiva bíblica: 
do espírito consigo mesmo [...], o concluir-se do espirito consigo mesmo não só na simplicidade da fé e da devoção do sentimento, mas também no pensar, em cuja simplicidade imanente tem igualmente expansão [que é] porém sabida como conexão indivisível do espírito universal, simples e eterno em si mesmo (Enz § 571; Enc-III, p. 350).

Os parágrafos acima da Enciclopédia indicam termos recorrentes em outros trechos da obra de Hegel que se debruçam sobre a lógica: "extremo", "negatividade", "mediação", "singular", "universal" e "verdade". Para os fins a que este artigo se propõe, convém sublinhar que Deus, descrito e inserido nos silogismos, emprega a função de conectivo entre o movimento lógico e a religião.

Nas Lições, o pensamento, a encarnação divina na dimensão humana, cuja primeira expressão de êxito está na figura de Jesus, bem como o apelo entre os indivíduos à membresia, são reconciliados por um mesmo índice de movimento encontrado na comunidade. Mas diferentemente da Filosofia do Direito, que afirmava ser o Estado o "divino terrestre" (IrdischGöttliches), aqui há uma instância divina e humana, ao mesmo tempo em que é a expressão máxima da liberdade, cujos predicados indicam que ela se trata de um arranjo social coeso $(G P h R \S 272$ A; $P R$, p. 258). Esta outra forma política, que não é o Estado, é mais estável e propícia para que a liberdade e a coesão social operem de modo otimizado, o que vem a ser propriamente a "comunidade".

A comunidade é um importante momento da percepção da liberdade, pressuposto, pela sua prática, da manutenção de uma memória ou arquivo de experiências socialmente compartilhado. Hegel alerta que a religião (que promove liberdade) e a ordem social não podem ser dissociados. Do mesmo modo como apenas o ser humano é capaz de possuir religião, a ele é também concedida eticidade (substancialidade livre). O caráter comunitário e distributivo da entidade eclesiástica é apresentado no $\$ 573$ da Enciclopédia (Enc-III, pp. 351-363), ao afirmar que a religião "é a forma da consciência da verdade disponível a todos” (cf. ROCKER, 1992, p. 32). A potência religiosa sobre todo Dasein, sobre toda a propriedade e sobre toda a vida é seria também uma confluência entre pensamento e direito. Em outras palavras, é a comunidade como o "povo vivo" (cf. ROSENZWEIG, 2008 [1919], p. 268).

A comunidade também expressa em nível ótimo a relação entre indivíduo e Deus em prol da autoconsciência. Nas Lições de 1827, Hegel expressa que "Deus está em relação com a consciência” ou, em outros termos, o espírito de Deus existindo essencialmente na forma de sua comunidade. Aqui se dá a relação que conserva a religião com a filosofia e com o Estado, mas não do Deus do sistema (cf. FERRARA, 1984, pp. xlviii-xlix). Desta feita, adverte Hegel, 
Deus só pode ser tratado na religião tal como Ele é para a comunidade. Uma vez que a religião não pode tomar Deus como outra coisa que não espírito, Deus assim se converte na contrafigura de uma comunidade e na atividade dessa comunidade que se refere a Ele (LFR-I, p. 31).

O surgimento do espírito na comunidade indica que o espírito se sabe Deus, que ele é atividade de si mesmo, e que se objetiva. Essa objetivação se dá no Filho de Deus. Hegel, então, argumenta que: a) Deus tem um Filho; b) o espírito testifica essa constatação; c) o espírito, por conseguinte, determina-se como unidade de ambos, Pai e Filho ${ }^{6}$. Esta unidade procura juntar a alteridade, superando-a no amor eterno (cf. LFR-III, p. 153). A compreensão lógico-metafísica de espírito é a sua conexão de substância e subjetividade, sendo o espírito elemento constitutivo para a vida ética, visto que é a comunidade decorrente da mediação entre o divino e o humano (cf. BUCHWALTER, 2018, pp. 33, 34).

\section{Considerações finais}

O presente artigo empreendeu o esforço de mostrar que o conceito de "comunidade", presente nas Lições sobre a filosofia da religião, configura um arranjo coletivo que conteria elementos de dimensão política, como mostra a Filosofia do Direito, bem como lógica, tal qual indica a Enciclopédia. As Lições evidenciam no contexto comunitário a instância de conciliação entre indivíduos e o absoluto em prol da autoconsciência a nível máximo. Para que tal ocorra, as particularidades seriam eliminadas a fim de que os limites e diferenças entre sujeito e objeto sejam suprassumidas. A comunidade, portanto, possuiria indicativos de que também aplica o resultado lógico do infinito (Deus) com o finito (humano) em ato, cuja manifestação silogística é visualizada nas etapas da criação e salvação do mundo na Enciclopédia. Uma vez que, na comunidade, a relação teórica com Deus não é suficiente, mas apenas um de seus elementos, exigindo sua execução prática, encontra-se aqui a oportunidade de trazer tal manifestação coletiva à luz da política. Não que os elementos religioso e político sejam alheios entre si, e que só se inter-relacionem após laboriosa argumentação e boa-vontade. As páginas de Hegel visitadas no presente artigo vislumbram a Igreja e o Estado como instâncias que não se encontram em oposição quanto ao conteúdo da verdade e da racionalidade, mas em uma diferença de forma. Enquanto a Igreja valoriza a doutrina, a sua fé e autoridade sobre o ético, o

\footnotetext{
${ }^{6}$ A assertiva de que a comunidade seria o espaço humano onde se dá a objetivação coletiva de Deus em espírito faz com que Labuschagne e Slootweg (2012, p. xxi) adotem a relação entre o culto religioso (causa) e sua expressão sociopolítica (efeito).
} 
direito, as leis e as instituições, o Estado passa a ser instância do conhecimento e prática destas instituições. O conteúdo religioso não deve permanecer apenas na forma do sentimento e da fé, mas pertence ao pensamento determinado.

No âmbito da verdade, a comunidade apresenta elementos que permitem a indicação de que ela seja uma versão daquilo que é político. Está subentendido que o indivíduo comprometido com a comunidade e que obedece às normas faz o bem, sendo inserido de modo otimizado no corpo político do Estado. Que reste claro não ter sido a intenção de Hegel fazer um elogio à teocracia, nem tornar a igreja em mais um aparelho estatal: a extensa nota ao $\$ 270$ da Filosofia do Direito apresenta argumentos que indicam o contrário. A religião e o Estado devem ser aptos a uma aliança orgânica. É possível depreender desse movimento que a recuperação do projeto político hegeliano é a justaposição do indivíduo e do cidadão como membro da comunidade mediante a aproximação e síntese com a dimensão transcendente. Visto que o presente texto objetivou conectar alguns aspectos da religião em Hegel com política e lógica, outros temas correlatos são suscitados nessa discussão, merecendo abordagem mais atenta: é o caso, por exemplo, da inserção mais aprofundada da Ciência da Lógica neste estudo. Todavia, dadas as questões de espaço textual, bem como o escopo ao qual este artigo se propôs, tais questões serão tratadas em outro momento.

\section{Referências bibliográficas}

\section{Referências primárias: obra de Hegel}

HEGEL, G. W. F. Ciencia de la Lógica. Trad. de Augusta Algranati e Rodolfo Mondolfo. Buenos Aires: Las Cuarenta, 2013.

Enciclopédia das ciências filosóficas - em compêndio (1830). 3 vol. Trad. Paulo Meneses e colaboração de José Machado. São Paulo: Loyola, 1995.

. Enzyklopädie der philosophischen Wissenchaften im Grundrisse (vols. 1-3). In: Werke in 20 Bänden, Bd. 8. Revisão Eva Moldenhauer e Karl Markus Michel. Frankfurt am Main: Suhrkamp Verlag, 1970.

Escritos de Juventud. Trad. de Zoltan Szankay e José María Ripalda. Madrid: Fondo de Cultura Económica, 1978.

Fenomenologia do espírito. Trad. Paulo Meneses. Petrópolis: Vozes, 2012.

Grundlinien der Philosophie des Rechts oder Naturrecht und Staatswissenschaft im Grundrisse. In: Werke im 20 Banden, Bd. 7. Revisão Eva Moldenhauer e Karl Markus Michel. Frankfurt am Main: Suhrkamp Verlag, 1970.

Lecciones sobre filosofía de la religión: 1. Introducción y Concepto de religión. Ed.

e Trad. Ricardo Ferrara. Madrid: Alianza Editorial, 1984. 
Lecciones sobre filosofía de la religión: 3. La religión consumada. Ed. e Trad. Ricardo Ferrara. Madrid: Alianza Editorial, 1985.

Editorial, 1982.

Lecciones sore la filosofía de la historia universal. Trad. José Gaos. Madrid: Alianza

Linhas fundamentais da filosofia do direito. Trad. de Paulo Meneses, Agemir

Bavaresco, Alfredo Moraes, Danilo Vaz-Curado R. M. Costa, Greice Ane Barbieri e Paulo

Roberto Konzen. São Leopoldo, RS: Ed. Unisinos, 2010.

. Outlines of the Philosophy of Right. Trad. T. M. Knox. Revisão Stephen Houlgate.

Nova York: Oxford University Press, 2008.

Phänomenologie des Geistes. In: Werke in 20 Bänden, Bd. 3. Revisão Eva Moldenhauer e Karl Markus Michel. Frankfurt am Main: Suhrkamp Verlag, 1970.

Vorlesungen über die Philosophie der Religion I-II-III, Bd 3-5. Revisão de Walter

Jaeschke. Hamburgo: Felix Meiner Verlag,1983-1985.

. Wissenschaft der Logik I. Erster Teil. Die objektive Logik. Erstes Buch. In: Werke in 20 Bänden, Bd. 5. Revisão Eva Moldenhauer e Karl Markus Michel. Frankfurt am Main: Suhrkamp, 1986.

Wissenschaft der Logik II. Erster Teil. Die objektive Logik. Zweites Buch. Zweiter Teil. Die subjektive Logik. In: Werke in 20 Bänden, Bd. 6. Revisão Eva Moldenhauer e Karl Markus Michel. Frankfurt am Main: Suhrkamp, 1986.

\section{Referências secundárias}

ALLAN, Donald J. (ed.). La politique d 'Aristote. Genebra: Fondation Hardt, 1965.

BOURGEOIS, Bernard. Le droit naturel de Hegel (1802-1803): commentaire. Paris: Vrin, 1986.

Hegel: os atos do espírito. Trad. Paulo Neves. São Leopoldo: Editora Unisinos, 2004. BUCHWALTER, Andrew. The Metaphysic of Spirit and Hegel's Philosophy of Politics. In: THOMPSON, Michael (org.). Hegel 's Metaphysics and the Philosophy of Politics. Nova York: Routledge, 2018.

CHAPELLE, Albert. Hegel et la religion: I, La problematique. Paris: Éditions Universitaires, 1964.

FERRARA, Ricardo. Apresentação. In: HEGEL, G, W. F. Lecciones sobre filosofía de la religión: 1. Introducción y Concepto de religión. Ed. e Trad. Ricardo Ferrara. Madrid: Alianza Editorial, 1984.

. "Prefácio Editorial". In: HEGEL, G. W. F. Lecciones sobre la filosofia de la religión, vol. 3: La Religión Consumada. Trad. Ricardo Ferrara. Madri: Alianza Editorial, 1985.

FERRARIN, Alfredo. Hegel and Aristotle. Cambridge: Cambridge University Press, 2001.

GIUSTI, Miguel. "Raíces metafísicas de la Lógica de Hegel”. Areté Revista de Filosofía, vol. VI, n. 1, 1994, pp. 49-59.

“Se puede prescindir de la Ciencia de la Lógica en la Filosofía del Derecho de 
Hegel?’'. Areté Revista de Filosofía, vol. XXV, n 1, 2013, pp. 45-60.

HERRMANN-SINAI, Susanne. "Hegel's Metaphysics of Action". In: DE LAURENTIIS, Allegra; WHITEHEAD, Soren (orgs.). Hegel and Metaphysics: On Logic and Ontology in the System. Berlim: De Gruyter, 2016.

HODGSON, Peter. Hegel and Christian Theology. Oxford: Oxford University Press, 2005.

HOULGATE, Stephen. The opening of Hegel's Logic. Purdue University Press, 2006.

JAESCHKE, Walter. Reason in Religion: The Foudantions of Hegel's Philosophy of Religion. Trad. J. Michael Stewart e Peter C. Hodgson. Berkeley: University of California Press, 1990

KAWAUCHE, Thomaz Massadi. Religião e política em Rousseau: o conceito de religião civil. São Paulo: Humanitas/Fapesp, 2013.

LABUSCHAGNE, Bart; SLOOTWEG, Timon (orgs.). Hegel's Philosophy of Historical Religions. Leiden: Brill, 2012.

LEWIS, Thomas A. Religion, Modernity, and Politics in Hegel. New York: Oxford University Press, 2011.

ROCKER, Stephen. "The Integral Relation of Religion and Philosophy in Hegel's Philosophy". In: KOLB, David (org.). New Perspectives on Hegel's Philosophy of Religion. Nova York: State University of New York Press, 1992.

ROSENFIELD, Denis Lerrer. Apresentação da tradução e atualidade da Filosofia do direito de Hegel. In: HEGEL, G. W. F. Linhas fundamentais da filosofia do direito. Trad. Paulo Meneses et al. São Leopoldo, RS: Ed. Unisinos, 2010.

Política e liberdade em Hegel. São Paulo: Ática, 1995.

ROSENZWEIG, Franz. Hegel e o Estado. Trad. de Ricardo Timm de Souza. São Paulo: Perspectiva, 2008.

SEMBOU, Evangelia. "Introduction”. In: SEMBOU, Evangelia (org.).The Young Hegel and Religion. Oxford: Peter Lang AG, 2017.

SOUAL, Philippe. Les sens de l'État: commentaire des Principes de la philosophie du droit de Hegel. Louvain: Éditions de l'Institut de Philosophie Louvain-la-Neuve, 2006.

VERRA, Valerio. Introduzione a Hegel. Roma-Bari: Editori Laterza, 1988.

WEBER, Thadeu. Hegel: liberdade, estado e história. Petrópolis: Vozes, 1993.

WILLIAMSON, Raymond K. Introduction to Hegel's Philosophy of Religion. Nova York: State University of New York Press, 1984. 